\title{
Subcutaneous Emphysema Is Iatrogenic Complication in Dental Surgery
}

\author{
Yara Mahfouz ${ }^{1}$, Maen Mahfouz ${ }^{1,2}$ \\ ${ }^{1}$ Dental Department, Al Zafer Hospital, Najran, Saudi Arabia \\ ${ }^{2}$ Department of Orthodontics and Pediatric Dentistry, Arab American University, Jenin, Palestine \\ Email: dr cuteee@yahoo.com, maenmahfouz@gmail.com
}

Received 24 July 2015; accepted 14 August 2015; published 17 August 2015

Copyright (c) 2015 by authors and Scientific Research Publishing Inc.

This work is licensed under the Creative Commons Attribution International License (CC BY).

http://creativecommons.org/licenses/by/4.0/

(c) (i) Open Access

\begin{abstract}
Subcutaneous emphysema in the head and neck is a well known clinical condition. It is an uncommon clinical complication of dental treatment caused by forceful injection of air into the loose connective tissue below the dermal layer. The trapped air is often limited by subcutaneous space in the head and neck. This paper presents a clinical case in which subcutaneous emphysema developed immediately during surgical extraction of third molar.
\end{abstract}

\section{Keywords}

Subcutaneous, Emphysema, Surgical Complication

\section{Introduction}

Subcutaneous emphysema is a rare occurrence in dental practice. It is usually benign and self-limiting [1]; nevertheless, severe consequences can result from surgical treatment. Emphysema occurs when air is injected into the subcutaneous layer of the tissue, this may come from either an air turbine handpiece or air syringe [2]. Due to the danger of developing emphysema, procedures using compressed air are not recommended in dental extractions involving the raising of a skin flap and bone sectioning. Early diagnosis and treatment are critical to prevent the trapped air leaking into other areas [3].

The first case of subcutaneous emphysema associated with a dental procedure was reported in 1900 [4]. Since then, it has been associated with air-generating dental instruments during restoration [5], surgical extraction [6]-[8], endodontic treatments [9], trauma from biopsy [10] and cheek biting [11].

The clinical presentation is characterized by a sudden onset of hemifacial swelling with fullness of the face and the eyelids on the involved side. Crepitation is noted on palpation and is almost pathognomonic for subcutaneous emphysema. 
The aim of this paper is to present a case of subcutaneous emphysema related to dental extraction, with raising a mucoperiosteal flap, possibly caused by close contact between the air turbine handpiece and the tooth during sectioning which forced air into the subcutaneous tissue.

\section{Case Presentation}

1) Case History

A 30-year-old male patient was referred by his dentist to the dental department of Al Zafer hospital with a chief compliant of Localized oral pain related to the lower left side of the oral cavity. He was in a full permanent dentition stage (Figures 1-5).

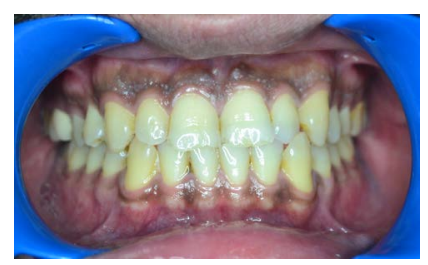

Figure 1. Frontal-intraoral view.

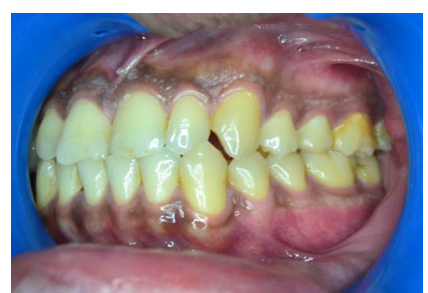

Figure 2. Left side-intraoral view.

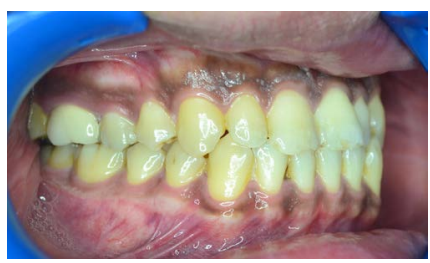

Figure 3. Right side-intraoral view.

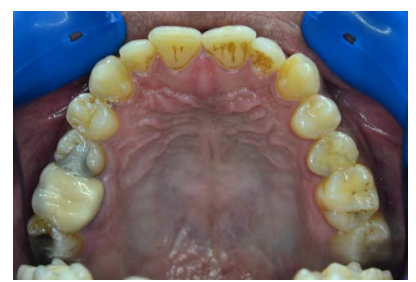

Figure 4. Intraoral occlusal view-upper jaw.

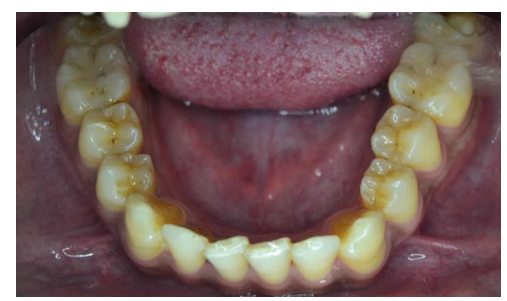

Figure 5. Intraoral occlusal view-lower jaw. 


\section{2) Diagnosis:}

The intraoral clinical examination revealed that all of the teeth were present and fully erupted except third molars in the lower jaw (Figures 1-6).

Panoramic radiograph indicated mandibular left third molar, which was impacted in the mandible, in horizontal position, with fused roots and near the mandibular canal (Figure 6).

3) Treatment Objectives: Eliminate the painful sensation in the oral cavity in addition to surgical removal of impacted third molar.

4) Treatment plan: Block anesthesia of the lower left side as well as incision of full thickness mucoperiosteal flap then sectioning the tooth to facilitate its removal after that irrigation, suturing, antibiotic coverage and follow up.

5) Treatment procedure:

After illustration for the patient an informed consent was taken. The offending area was anesthetized using inferior alveolar nerve block technique in which long needle with 27 gauge had used. Once the signs indicating block anesthesia had achieved, a triangular surgical flap was made with a release incision mesially to the second molar and adjacent to the papilla. The mucoperiosteal flap was raised, exposing the overlying bone and maintained with a langenbeck retractor. In order to expose the tooth crown, ostectomy was performed using a surgical stainless steel bur on a low-speed straight handpiece with copious sterile saline irrigation. Then, an air-driven high-speed turbine was used for tooth sectioning.

During the sectioning procedure, the patient reported a swelling of his face with mild upper neck pain on the same side. An immediate swelling was observed of the upper and lower cheek and lower left eyelid, accompanied by audible and palpable crepitus (Figures 7-10).

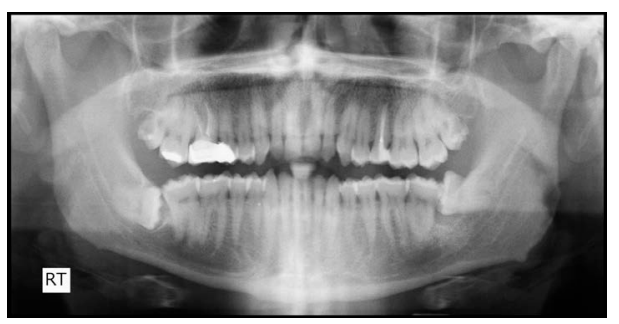

Figure 6. Panoramic radiograph.

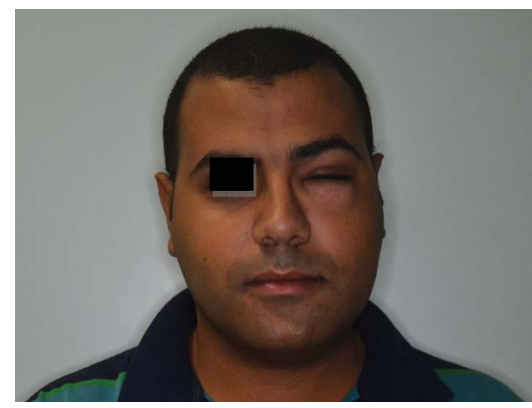

Figure 7. Frontal-extraoral view.

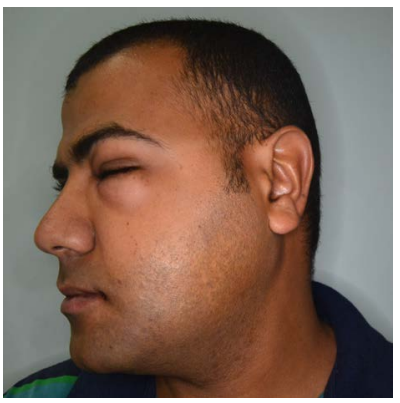

Figure 8. Lateral-extraoral view. 


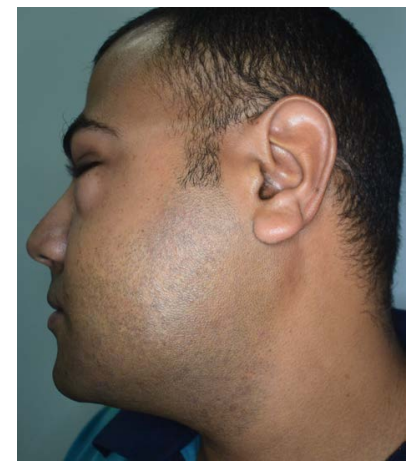

Figure 9. Lateral-extraoral view.

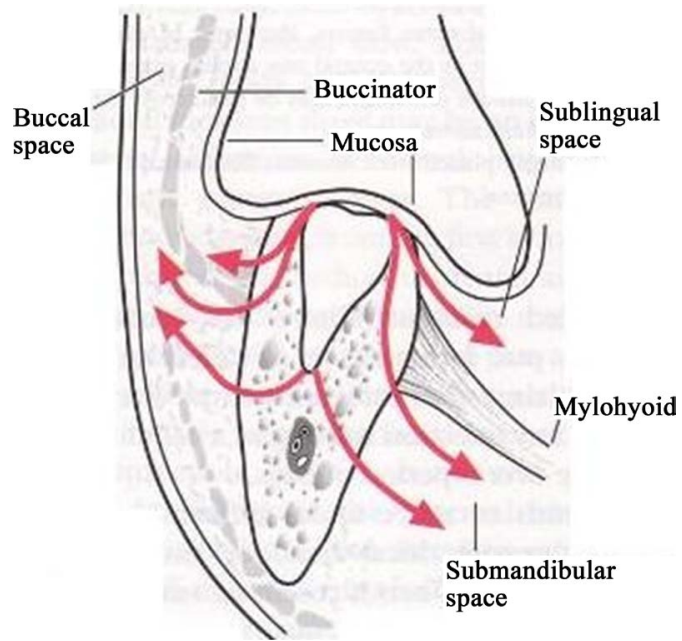

Figure 10. Schematic representation of the air spreading through facial spaces during tooth sectioning by air driven handpiece.

At that moment the patient has been given assurance about his situation in addition, stopping the work using air driven handpiece followed by sequeezing the cheek of the patient and finally giving him 100 MG of hydrocortisone injection.

After tooth removal was completed, abundant saline irrigation was performed and the flap was sutured using a $3 / 0$ silk sutures. Post-operative periapical radiograph was taken to be ascertained that no any residual fragments of tooth structure (Figure 11). Chemotherapy consisted of a non steroidal antiinflammatory (Ibuprofen 600 mg/8hours) and antibiotics (Amoxicillin-ac. 500 mg/8hours/7days—Metronidazole. 500 mg/8hours/7days).

6) Recall visits

Follow-up visits were scheduled on a 2-day basis. After 48 hours the facial swelling had reduced slightly and the symptoms were less severe (Figure 12 and Figure 13). Stitches were removed a week after surgery and on examination the patient was found to be asymptomatic on the following two successive weeks (Figures 14-17).

\section{Discussion}

Subcutaneous emphysema is an uncommon complication in dental routine. In dental literature there is availability of different reviews of complications regarding emphysema and dental procedures since 1960 till 2009. Heyman and Babayof [12] described 74 cases, 71\% related with the use of an air syringe, high-speed handpiece or both; concluding that this is not a rare complication, being caused principally by dental extractions and restorative procedures. They have reported that subcutaneous emphysema affects the upper neck in $95 \%$ and the eye socket area in $45 \%$ of cases. Both areas were affected in the case presented in this study. Arai et al. [2] included a review of 47 clinical cases of subcutaneous emphysemas and pneumomediastinum treated between 1994 and 2008, 18 of which appeared after a dental extraction. McKenzie and Rosenberg [13] reviewed 32 cases 


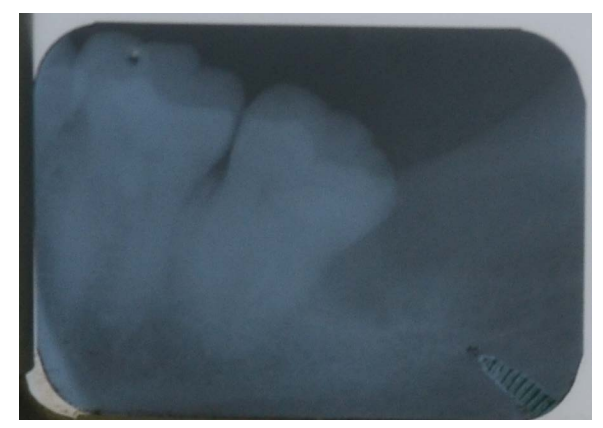

Figure 11. Postoperative periapical radiograph.

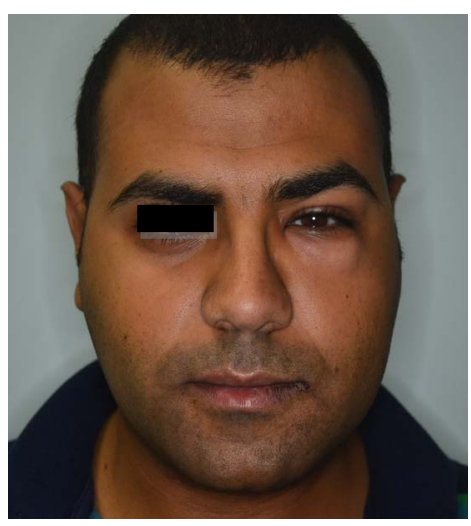

Figure 12. Frontal-extraoral view after 2 days.

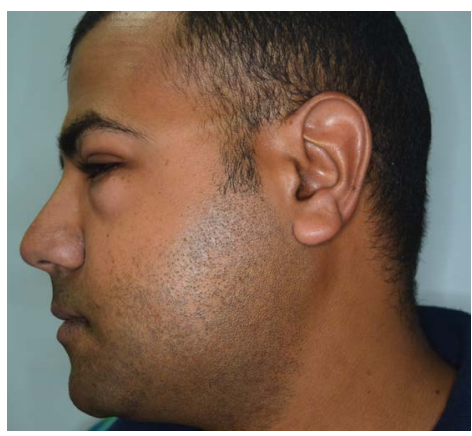

Figure 13. Lateral—extraoral view after 2 days.

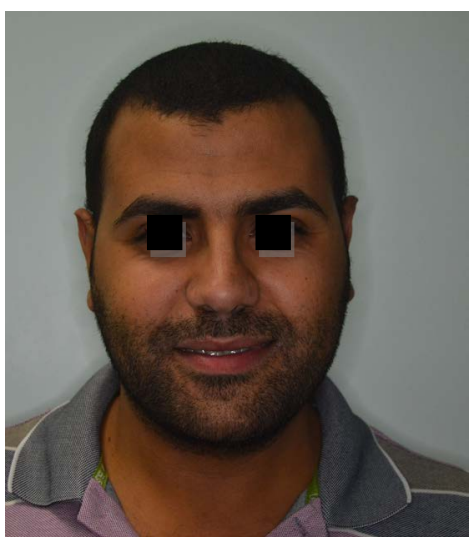

Figure 14. Frontal—extraoral view after one week. 


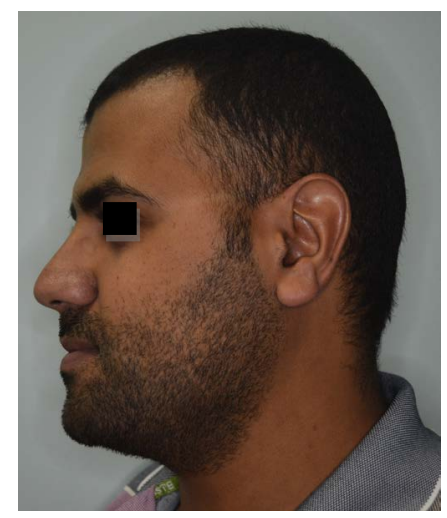

Figure 15. Lateral—extraoral view after one week.

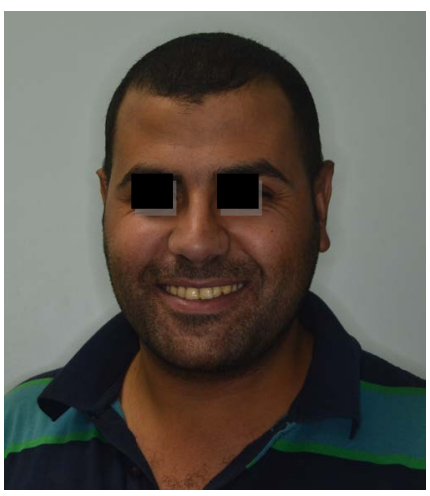

Figure 16. Lateral—extraoral view after two weeks.

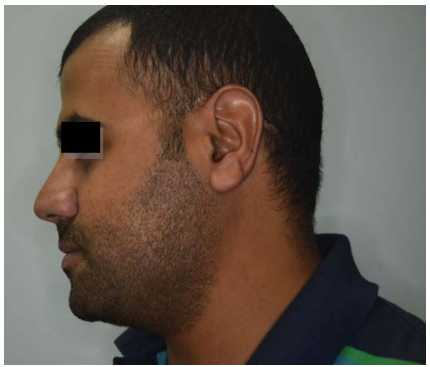

Figure 17. Lateral—extraoral view after two weeks.

of subcutaneous emphysema produced during surgical procedures between 1993 and 2008. They noticed that dental extraction was involved in 7 cases (6 for using an air-driven handpiece and the other of unspecifed origin).

Two determining factors are always involved with subcutaneous emphysema. On the one hand, a compressed air procedure (air turbine handpiece, air-water syringe), and on the other, a communication between the oral cavity and deeper tissue producing dissection [3] (Figure 10).

In the current clinical case during the surgical phase, the air turbine handpiece was inclined towards the buccal face of the tooth to avoid damage to the lingual nerve. The handpiece was therefore "immersed" within the flap that was incorrectly held in place by the dental assistant. The air produced by the turbine followed the free way constituted by the partially disinserted fibers of the masseter muscle. Almost immediately after tooth sectioning, the left side of the patient's face became swollen from the inferior border of the mandible to the attachment of the temporalis muscle. The swelling immediately closed the patient's left eye. The patient did not have pain, tenderness to palpation, or difficulty breathing as a result of the swelling. However, he did note a fullness sensation of his face and he could not open his left eye (Figures 7-10).

Subcutaneous emphysema usually resorbs spontaneously without complications, and its treatment is sympto- 
matic, as in the present case [14]. Clinical improvement is noted after 2 - 3 days, with minimal crepitus after 7-10 days. Antibiotic prophylaxis is accepted, since the air introduced through an intraoral location is likely to carry bacteria that can cause cellulitis or necrotizing fasciitis [12].

To avoid the occurrence of this rare surgical complication, Sekine et al. [15] recommend that any mucoperiosteal flap raised during a dental extraction should be kept as small as possible and not extend towards the lingual area of the molar alveoli. While Gamboa et al. [16] indicated that caution should be exercised with periodontal pockets over $4 \mathrm{~mm}$ or when there is little adhered gingiva due to the increased susceptibility of producing emphysema. In addition, it is recommended to maintain the greatest possible distance between the handpiece and the soft tissues and/or bone to prevent penetration of air, even in the absence of a mucoperiosteal flap. Finally handpieces that exhaust air into the surgical field should not be used. Air-cooled instruments used in surgical orofacial procedures should vent air away from the immediate area or recirculate the air to reduce the risk of introducing it into tissues.

The differential diagnosis of sudden onset head and neck swelling after dental procedures includes hematoma, cellulitis, allergic reaction, angioedema and subcutaneous emphysema [17]. Anaphylaxis (loss of vascular tone indicated by a precipitous fall in blood pressure caused by contact with an allergen) would result in more profuse, bilateral facial manifestations with possible cardiorespiratory symptoms. Angioedema (a massive escape of fluid into the tissue from blood vessels causing large edematous swellings) usually appears in the maxilla as a reddened area with well circumscribed rings and a burning sensation. Hematoma (a pooling of blood in tissues) can also be suspected, although crepitus is not usually present.

In over $90 \%$ of cases, the onset of emphysema-based swelling occurs either during surgery or within 1 hour afterward [18]. Considered an unexpected complication clinical presentation and course are generally predictable. The clinical features of cervicofacial emphysema following dental surgery commonly involve the initial symptoms of swelling due to a foreign, space-occupying material in the soft tissue-in this case air (Table 1). The area rapidly becomes swollen and mild crepitus is detected when the tissue is palpated. Local discomfort is slight and is due only to tenseness of the tissues [19]. Limited inflammation of the tissue is observed. Trismus may also be present but is site dependent and often slight. More serious emergency situations arise with the spread of air into the para- and retropharyngeal spaces potentially resulting in respiratory difficulty with risk of airway embarrassment. Migration to the thorax and mediastinum may result in compromised respiratory and cardiac function with possible death.

The treatment of subcutaneous emphysema varies with the severity of the condition and the experience of the physician. Most cases will begin to resolve after 2 - 3 days of supportive treatment with complete resolution after 7 - 10 days [20]. Observation for potential airway embarrassment, cardiovascular or infectious processes is often all that is required. Surgical decompression of extensive emphysema should not be routinely undertaken as it is not likely to be effective and may increase or spread the entrapped gas [21]. The potential for infection is also a concern as the air entering the tissues is contaminated with oral bacteria [22]. Post-resolution purulence within the fascial spaces has been reported [23]. Penicillin is an empirical first choice due to its appropriate narrow-spectrum coverage of normal oral flora [5]. Analgesics are prescribed as necessary, but are rarely required as discomfort is often minimal. In most cases, patients can be reassured with an explanation of the nature and course of the process. Patients should be cautioned to return in the case of increased swelling or difficulty breathing [24].

\section{Conclusions}

1) The occurrence of sudden swelling during a dental procedure, marked by crepitus within the soft tissue, should raise suspicion of subcutaneous emphysema.

2) Handpieces that exhaust air into the surgical field should not be used. Air-cooled instruments used in surgical

\begin{tabular}{lcc} 
Table 1. Clinical features of cervicofacial emphysema. \\
\hline \\
Clinical features of cervicofacial emphysema & Early & Late \\
& Crepitus & Diffuse swelling \\
& Local discomfort & Pain \\
\hline
\end{tabular}


orofacial procedures should vent air away from the immediate area or recirculate the air to reduce the risk of introducing it into tissues.

\section{References}

[1] García Egido, A.A., García Herrera, A.L. and Domínguez Fuentes, B. (2008) Subcutaneous Emphysema and Pneumomediastinum after Dental Extraction. Medicina Clínica, 130, 518. http://dx.doi.org/10.1157/13119496

[2] Arai, I., Aoki, T., Yamazaki, H., Ota, Y. and Kaneko, A. (2009) Pneumomediastinum and Subcutaneous Emphysema after Dental Extraction Detected Incidentally by Regular Medical Checkup: A Case Report. Oral Surgery, Oral Medicine, Oral Pathology, Oral Radiology, and Endodontology, 107, e33-e38. http://dx.doi.org/10.1016/j.tripleo.2008.12.019

[3] Peñarrocha, M.A., Ata-Ali, J., Carrillo, C. and Peñarrocha, M. (2011) Subcutaneous Emphysema Resulting from Surgical Extraction without Elevation of a Mucoperiosteal Skin Flap. Journal of Clinical and Experimental Dentistry, 3, e265-e267. http://dx.doi.org/10.4317/jced.3.e265

[4] Turnbull, A. (1900) A Remarkable Coincidence in Dental Surgery. British Medical Journal, 1, 1131. http://dx.doi.org/10.1136/bmj.1.2053.1131-b

[5] Karras, S.C. and Sexton, J.J. (1996) Cervicofacial and Mediastinal Emphysema as the Result of a Dental Procedure. The Journal of Emergency Medicine, 14, 9-13. http://dx.doi.org/10.1016/0736-4679(95)02037-3

[6] Nobel, W.H. (1972) Mediastinal Emphysema Resulting from Extraction of an Impacted Mandibular Third Molar. The Journal of the American Dental Association, 84, 368-370. http://dx.doi.org/10.14219/jada.archive.1972.0044

[7] Horowitz, I., Hirshberg, A. and Freedman, A. (1987) Pneumomediastinum and Subcutaneous Emphysema Following Surgical Extraction of Mandibular Third Molars: Three Case Reports. Oral Surgery, Oral Medicine, Oral Pathology, 63, 25-28. http://dx.doi.org/10.1016/0030-4220(87)90335-5

[8] Buckley, M.J., Turvey, T.A., Schummann, S.P. and Grimson, B.S. (1990) Orbital Emphysema Causing Vision Loss after a Dental Extraction. The Journal of the American Dental Association, 120, 421-424. http://dx.doi.org/10.14219/jada.archive.1990.0122

[9] Smatt, Y., Browaeys, H., Genay, A., Raoul, G. and Ferry, J. (2004) Iatrogenic Pneumomediastinum and Facial Emphysema after Endodontic Treatment. British Journal of Oral and Maxillofacial Surgery, 42, 160-162. http://dx.doi.org/10.1016/S0266-4356(03)00240-7

[10] Staines, K. and Felix, D.H. (1998) Surgical Emphysema: An Unusual Complication of Punch Biopsy. Oral Diseases, 4, 41-42. http://dx.doi.org/10.1111/j.1601-0825.1998.tb00254.x

[11] Yamada, H., Kawaguchi, K., Tamura, K., Sonoyama, T., Iida, N. and Seto, K. (2006) Facial Emphysema Caused by Cheek Bite. International Journal of Oral and Maxillofacial Surgery, 35, 188-189. http://dx.doi.org/10.1016/j.ijom.2005.07.001

[12] Heyman, S.N. and Babayof, I. (1995) Emphysematous Complications in Dentistry, 1960-1993: An Illustrative Case and Review of the Literature. Quintessence International, 26, 535-543.

[13] Mckenzie, W.S. and Rosenberg, M. (2009) Iatrogenic Subcutaneous Emphysema of Dental and Surgical Origin: A Literature Review. Journal of Oral and Maxillofacial Surgery, 67, 1265-1268. http://dx.doi.org/10.1016/j.joms.2008.12.050

[14] Kung, J.C., Chuang, F.H., Hsu, K.J., Shih, Y.L., Chen, C.M. and Huang, I.Y. (2009) Extensive Subcutaneous Emphysema after Extraction of a Mandibular Third Molar: A Case Report. Kaohsiung Journal of Medical Sciences, 25, 562566. http://dx.doi.org/10.1016/S1607-551X(09)70550-9

[15] Sekine, J., Irie, A., Dotsu, H. and Inokuchi, T. (2000) Bilateral Pneumothorax with Extensive Subcutaneous Emphysema Manifested during Third Molar Surgery. A Case Report. International Journal of Oral and Maxillofacial Surgery, 29, 355-357. http://dx.doi.org/10.1016/S0901-5027(00)80051-X

[16] Gamboa Vidal, C.A., Vega Pizarro, C.A. and Almeida A.A. (2007) Subcutaneous Emphysema Secondary to Dental Treatment: Case Report. Medicina Oral Patologia Oral Y Cirugia Bucal, 12, E76-E78.

[17] Pynn, B.R., Amato, D. and Walker, D.A. (1992) Subcutaneous Emphysema Following Dental Treatment: A Report of Two Cases and Review of the Literature. The Journal of the Canadian Dental Association, 58, 496-499.

[18] Monsour, P.A. and Savage, N.W. (1989) Cervicofacial Emphysema Following Dental Procedures. Australian Dental Journal, 34, 403-406. http://dx.doi.org/10.1111/j.1834-7819.1989.tb00695.x

[19] Shackelford, D. and Casani, J.A. (1993) Diffuse Subcutaneous Emphysema, Pneumomediastinum, and Pneumothorax after Dental Extraction. Annals of Emergency Medicine, 22, 248-250. http://dx.doi.org/10.1016/S0196-0644(05)80214-8

[20] Peterson, L.J. (1990) Emphysema and the Dental Drill. The Journal of the American Dental Association, $120,423$. 
[21] Chen, S.C., Lin, F.Y. and Chang, K.J. (1999) Subcutaneous Emphysema and Pneumomediastinum after Dental Extraction. American Journal of Emergency Medicine, 17, 678-680. http://dx.doi.org/10.1016/S0735-6757(99)90158-4

[22] Aragon, S.B., Dolwick, M.F. and Buckley, S. (1986) Pneumomediastinum and Subcutaneous Cervical Emphysema during Third Molar Extraction under General Anesthesia. Journal of Oral and Maxillofacial Surgery, 44, 141-144. http://dx.doi.org/10.1016/0278-2391(86)90198-9

[23] Cardo Jr., V.A., Mooney, J.W. and Stratigos, G.T. (1972) Iatrogenic Dental Air Emphysema: Report of a Case. The Journal of the American Dental Association, 85, 144-147. http://dx.doi.org/10.14219/jada.archive.1972.0283

[24] Mather, A.J., Stoykewych, A.A. and Curran, J.B. (2006) Cervicofacial and Mediastinal Emphysema Complicating a Dental Procedure. Journal of the Canadian Dental Association, 72, 565-568. 